\title{
Novel Self-Assembled MgO Nanosheet and its Precursors
}

\author{
Chenglin Yan and Dongfeng Xue ${ }^{*}$
}

State Key Laboratory of Fine Chemicals and School of Chemical Engineering, Dalian

University of Technology, 158 Zhongshan Road, Dalian 116012, China

*Corresponding author. E-mail: dfxue@chem.dlut.edu.cn

In this work, we try to deeply understand the growth mechanism of nestlike $\mathrm{Mg}_{5}\left(\mathrm{CO}_{3}\right)_{4}(\mathrm{OH})_{2} \cdot 4 \mathrm{H}_{2} \mathrm{O}$ spheres, which can be regarded as a kind of self-assembled process. Therefore, we try to observe their morphologies at different growth stages, such as different growth periods.

\section{Period 1:}

Only very tiny spheres can be seen when the reaction time reaches $1 \sim 2$ hours, as shown below. Such spheres can be regarded as the initial nuclei of $\mathrm{Mg}_{5}\left(\mathrm{CO}_{3}\right)_{4}(\mathrm{OH})_{2} \cdot 4 \mathrm{H}_{2} \mathrm{O}$ compounds.
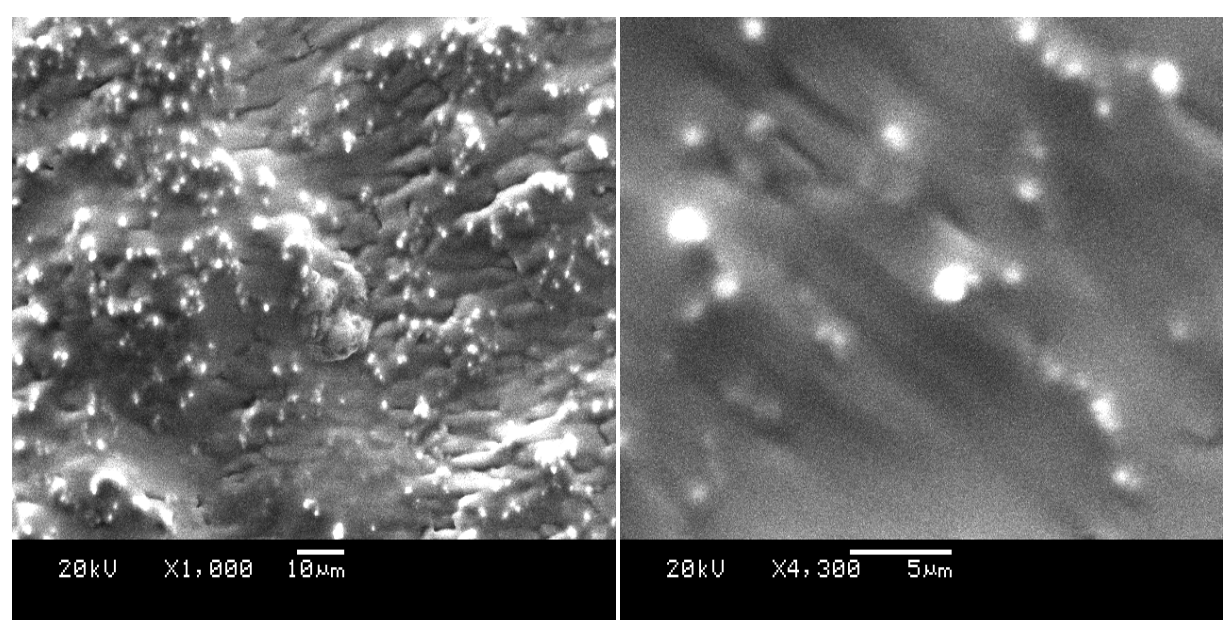


\section{Period 2:}

Many spheres can be seen when the reaction time reaches $\sim 2.5$ hours, as shown below. Such spheres are composed of disordered $\mathrm{Mg}_{5}\left(\mathrm{CO}_{3}\right)_{4}(\mathrm{OH})_{2} \cdot 4 \mathrm{H}_{2} \mathrm{O}$ nanosheets, which are stacked each other very loosely. It can be concluded that such spheres are self-assembled while growing. The color arrow shows that $\mathrm{Mg}_{5}\left(\mathrm{CO}_{3}\right)_{4}(\mathrm{OH})_{2} \cdot 4 \mathrm{H}_{2} \mathrm{O}$ nanosheets are not yet well assembled at this time.
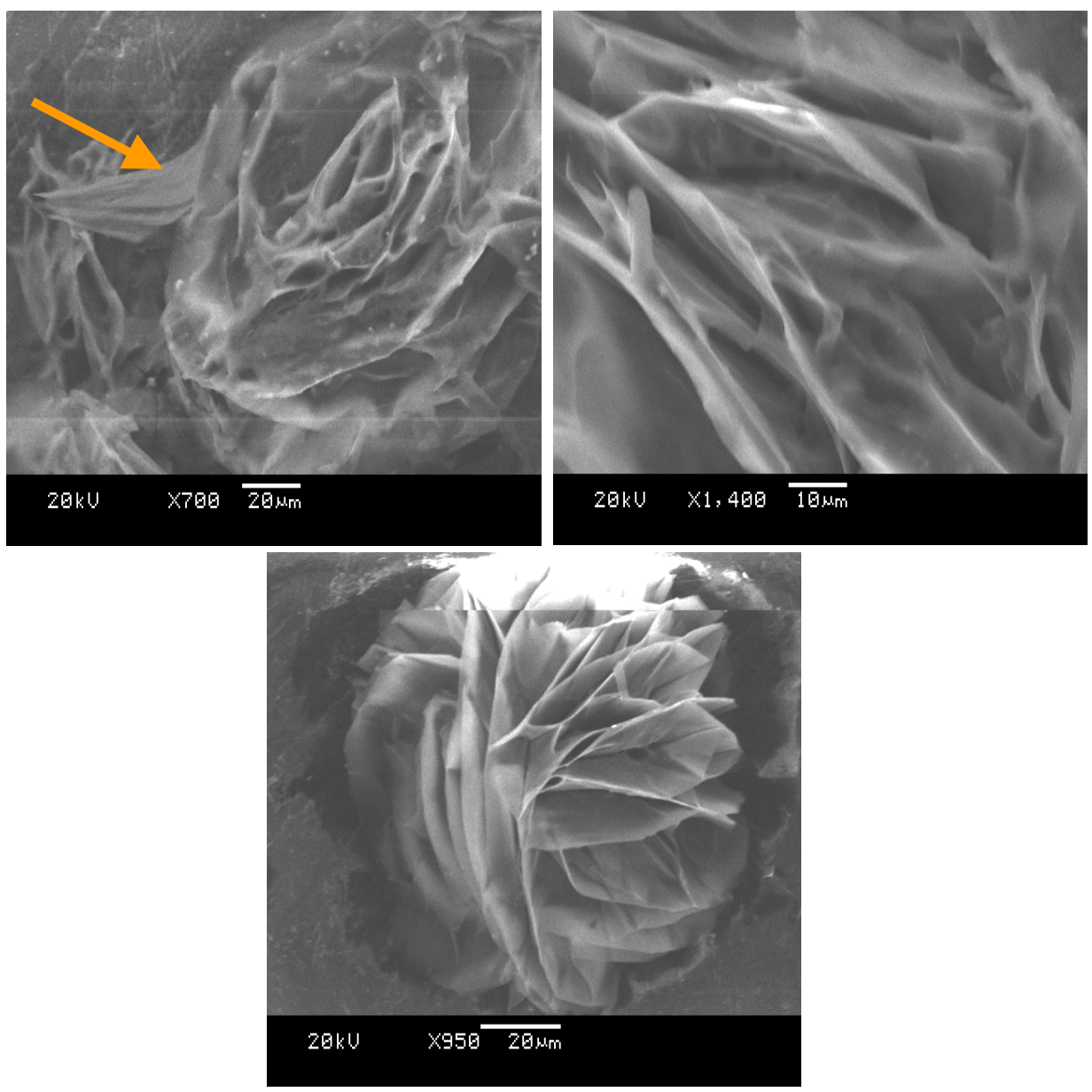


\section{Period 3:}

When the reaction time reaches 3 hours, $\mathrm{Mg}_{5}\left(\mathrm{CO}_{3}\right)_{4}(\mathrm{OH})_{2} \cdot 4 \mathrm{H}_{2} \mathrm{O}$ nanosheets in many of these spheres become tight, as shown below. It can also be seen that at this stage disordered $\mathrm{Mg}_{5}\left(\mathrm{CO}_{3}\right)_{4}(\mathrm{OH})_{2} \cdot 4 \mathrm{H}_{2} \mathrm{O}$ nanosheets become ordered. The color arrows show that $\mathrm{Mg}_{5}\left(\mathrm{CO}_{3}\right)_{4}(\mathrm{OH})_{2} \cdot 4 \mathrm{H}_{2} \mathrm{O}$ nanosheets are not yet well assembled into well-shaped spheres at this time.
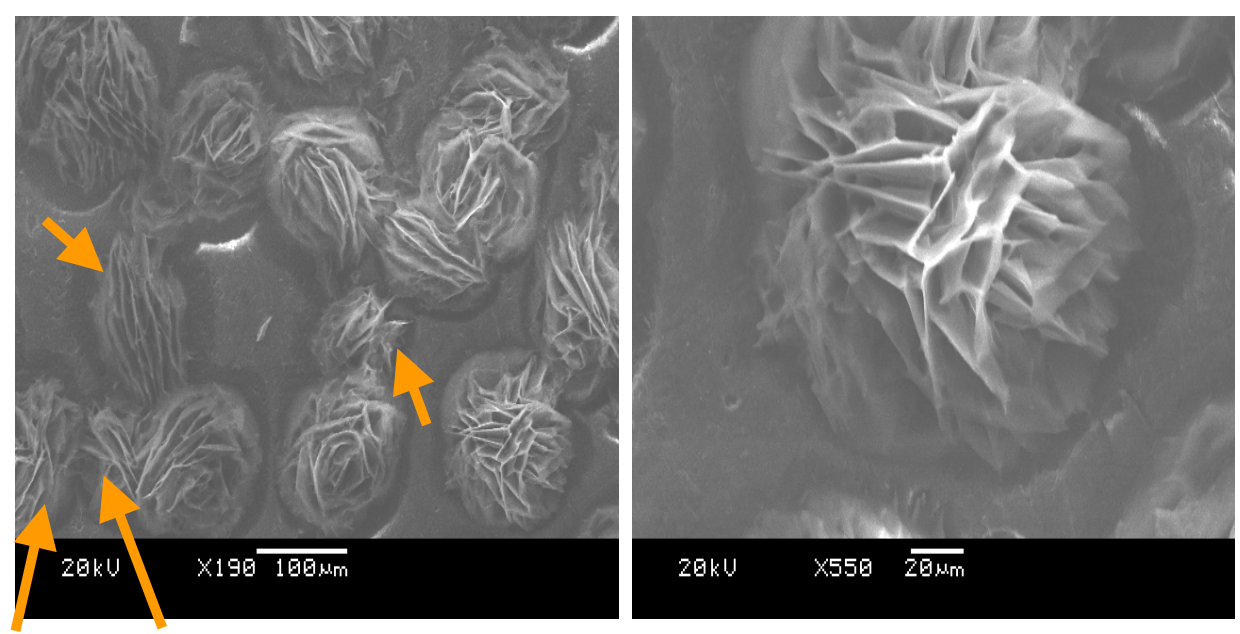

\section{Period 4:}

Well self-assembled nestlike $\mathrm{Mg}_{5}\left(\mathrm{CO}_{3}\right)_{4}(\mathrm{OH})_{2} \cdot 4 \mathrm{H}_{2} \mathrm{O}$ (with a very smooth surface) can be obtained when the reaction time reaches 3.5 4 hours, as shown in Figure 2 in the text. 